\title{
Dried blood spots in HIV monitoring: applications in resource-limited settings
}

By the end of 2008, 4 million people were receiving antiretroviral treatment for HIVIAIDS in low- and middleincome countries. In industrialized countries, monitoring of treatment with viral load measurements and drug resistance testing is the standard of care to ensure early detection of treatment failure and a prompt switch to a fully active second-line regimen, before drug-resistant mutations accumulate. These tests, however, require highly specialized laboratories and stringent procedures for storage and shipment of plasma, and are rarely available in resource-limited settings. Therefore, treatment failure in such settings is usually not detected until patients develop severe immunodeficiency, at which stage widespread resistance is likely. Dried blood spots (DBS) are easy to collect and store, and can be a convenient alternative to plasma in settings with limited laboratory capacity. This review provides an overview of possible applications of DBS technologies in the monitoring of HIV treatment, with the main focus on viral load quantification and drug resistance testing.

\section{Scale-up of antiretroviral treatment in resource-limited settings}

Since the discovery of AIDS in 1981 and the identification of HIV 2 years later, HIV/AIDS has evolved into one of our time's most devastating pandemics. By the end of 2008, 33.4 million people were living with HIV/AIDS, the majority of whom reside in sub-Saharan AfricA) Furthermore, 2.7 million individuals were newly infected with HIV in 2008, and 2 million AIDS-related deaths occurred the same year [1].

For many years HIV/AIDS was a death sentence, even in wealthy countries with good access to healthcare. From 1996, however, the introduction of a new class of antiretroviral drugs (protease inhibitors) and the advent of highly active antiretroviral therapy (combination therapy of at least three antiretroviral drugs) radically changed the prognosis for people living with HIV/AIDS. HIV-infected individuals who receive antiretroviral treatment (ART) are now able to live normal lives with a life expectancy that might approach that of non-HIV-infected individuals, particularly when treatment is initiated before severe immunodeficiency has developed [2].

Until recently, the vast majority of HIVinfected individuals worldwide did not have access to HIV treatment, due to poverty and lack of healthcare infrastructure. Over the past years, however, the WHO, the Joint United Nations Programme on HIV/AIDS (UNAIDS), and international nongovernmental organizations have led a massive public health campaign aiming for universal access to ART. Simultaneously, generic competition has brought down prices of antiretroviral drugs from more than US $\$ 10,000$ to less than US $\$ 70$ per person per year [101]. The introduction of fixed-dose combination tablets has further simplified treatment, so that many patients now have regimens consisting of one or two tablets per day.

By the end of 2008, more than 4 million people were receiving ART in low- and middleincome countries, which is a tenfold expansion over the past 5 years [3]. Several reports have documented beneficial effects of ART on HIVassociated morbidity and mortality in resourcelimited settings [4-6], and ART can also effectively prevent HIV transmission from pregnant women to their children [7]. Nevertheless, as more and more patients are receiving ART worldwide, huge challenges remain in terms of ensuring long-term efficacy of therapy.

\section{Monitoring of antiretroviral treatment} In high-income countries, patients who receive ART are monitored regularly with HIV-1 RNA viral load measurements and genotypic resistance testing. Effective therapy should suppress the viral load to undetectable levels by 24 weeks and thereafter maintain full viral suppression. Patients with consistent viral load elevations during treatment should be tested for genotypic resistance, so that their ART regimen can be modified according to their resistance profile $[8,9]$.

\section{Asgeir Johannessen}

Department of Infectious Diseases, Oslo University Hospital, Ulleval, Oslo, Norway

Tel.: +47979 83264

Fax: +47221 191 81

E-mail: asgeir.johannessen@

medisin.uio.no 


\section{Key terms}

Antiretroviral treatment:

Combination of three or more anti-HIV drugs.

Viral load: Amount of RNA from HIV-I in the blood (usually measured in plasma).

\section{Genotypic resistance} testing: Genetic sequencing of the HIV-I genome to detect mutations that confer resistance to antiretroviral drugs.

Dried blood spots: Whole blood spotted and dried on a filter paper card.
Early detection of treatment failure and prompt switch to a fully active second-line regimen is the key to preventing accumulation of drug-resistant mutations, which could jeopardize future drug options [10]. Furthermore, effective suppression of viral replication is crucial to avoid the negative consequences of HIV infection [11].

In resource-limited settings, however, viral load measurements and genotypic resistance testing are rarely available due to their high costs, complexity and stringent requirements for storage and transport of plasma. Hence, after a patient has initiated ART, it is often impossible to determine whether the treatment is effective or not. In settings without access to viral load monitoring, the WHO recommends to detect treatment failure by clinical (new or recurrent WHO stage 4 condition) or immunological (impaired CD4 cell response) criteria [12,13]; however, recent studies have shown that these criteria have poor sensitivity and specificity in detecting true virological failure [14,15]. Using the WHO criteria, the majority of patients with treatment failure will not be detected until they develop severe immunodeficiency or opportunistic disease, at which stage widespread resistance is likely [16]. Furthermore, many patients will be misclassified as treatment failures despite adequate virological response, and risk premature switch to complex and expensive second-line therapy [17].

Thus, a vital question in the scale-up of ART remains: how can HIV viral load and drug resistance be monitored in settings with limited laboratory capacity? Although ART has become cheaper, simpler and more available over the past decade, the laboratory equipment needed to monitor treatment is still expensive, complex and unavailable to most HIV-infected individuals worldwide. The current review presents the potential utility of dried blood spots (DBS) for monitoring of patients who receive ART in resource-limited settings. Relevant studies on the use of DBS for viral load quantification, genotypic resistance testing and other HIVrelated analyses are presented. Furthermore, the limitations of these methods and unresolved issues are discussed.

\section{Advantages of DBS where there is limited laboratory capacity}

Dried blood spots can be a practical tool to overcome the challenges associated with storage and transport of blood specimens in settings with limited infrastructure. Plasma samples require a trained phlebotomist, electricity for centrifugation, a freezer for storage and ultimately a functioning cold chain and speedy transport to the laboratory. DBS, on the other hand, are prepared by spotting whole blood onto a filter paper, either from venous blood or directly from a finger prick, making this method particularly suitable in rural settings where laboratory personnel are scarce. Furthermore, DBS packed in ziplock plastic bags with desiccant can be stored and shipped at ambient temperature, thus avoiding the requirement for a freezer and carriage on dry ice. DBS specimens can be sent by truck or bus to the reference laboratory or simply by the postal system where available. Biohazard risks associated with shipment are minimized since DBS cannot break and HIV on the filter paper matrix loses infectivity on drying.

\section{Current use of DBS in pediatric screening programs}

Dried blood spots have been used for more than 40 years to screen for metabolic disorders in neonates [18]. Recently, several African countries, including South Africa (which has the world's largest HIV-positive population) started to use DBS to screen for HIV in infants born of HIV-infected mothers. These infants cannot be tested by ordinary antibody tests, since passively transferred maternal antibodies can persist in their circulation for up to 18 months postpartum. Detection of HIV-1 DNA in DBS by PCR, however, is a highly sensitive and specific test of HIV infection in infants [19]. Performed at the routine 6 -week immunization clinic visit, this test is able to identify most infants infected pre- and peri-natally. Consequently, pediatric ART can be initiated at an early stage, which is key to reducing the high mortality in this group [20].

Hence, the use of DBS is already familiar to healthcare providers and laboratory technicians in several low-income countries, and this can serve as a model for further expansion of DBS monitoring strategies in such settings.

\section{HIV-I viral load quantification using DBS}

Several studies have assessed the use of DBS for HIV-1 viral load quantification [21-42]. TABLE I summarizes studies comparing HIV-1 RNA levels in DBS with a gold standard plasma method.

The majority used anticoagulated whole blood obtained by venipuncture to prepare the dried spots. The input volume per spot was either 50 or $100 \mu \mathrm{l}$, or unspecified. DBS specimens were air dried from $30 \mathrm{~min}$ to $24 \mathrm{~h}$. All studies used 903 


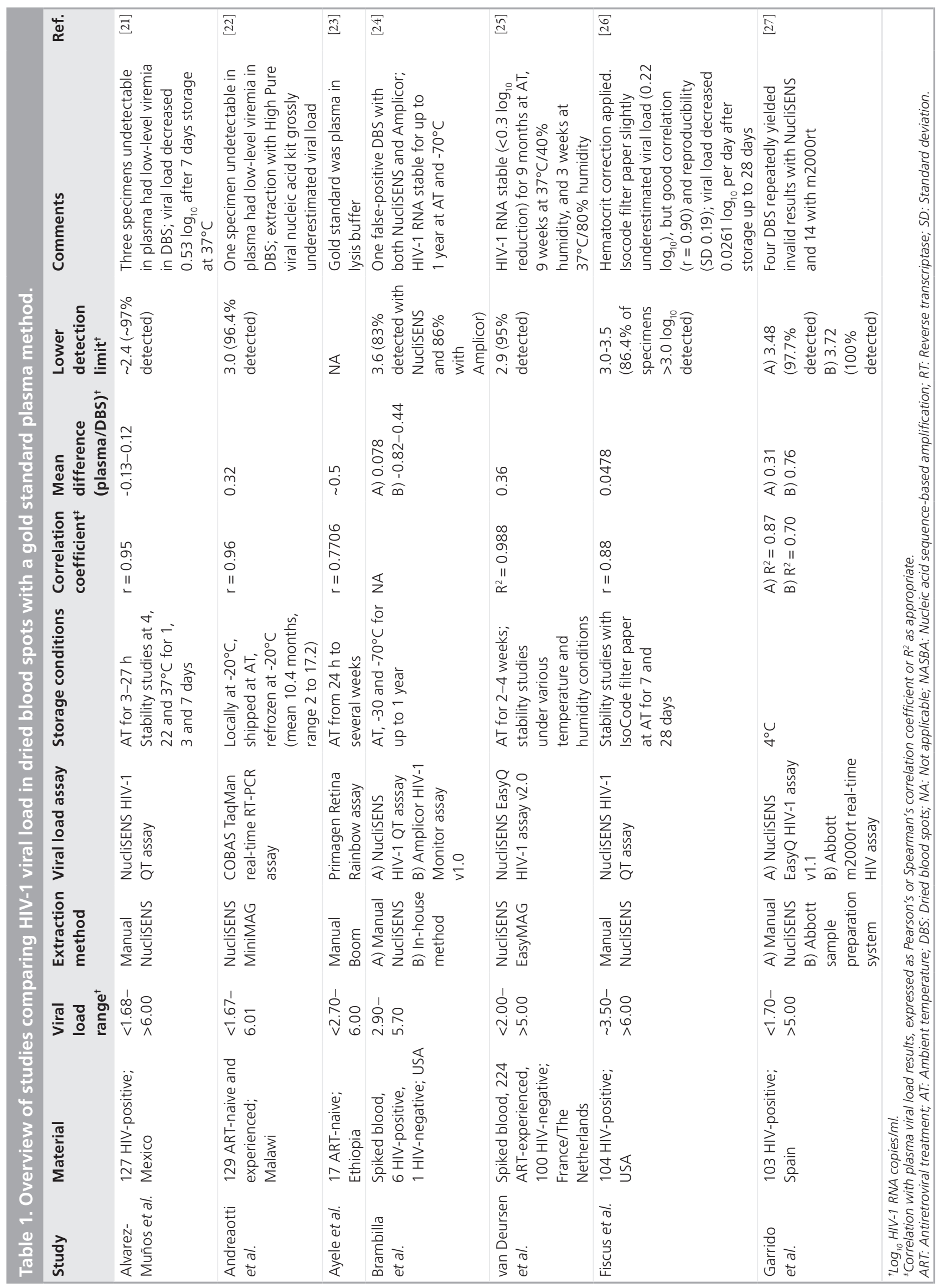




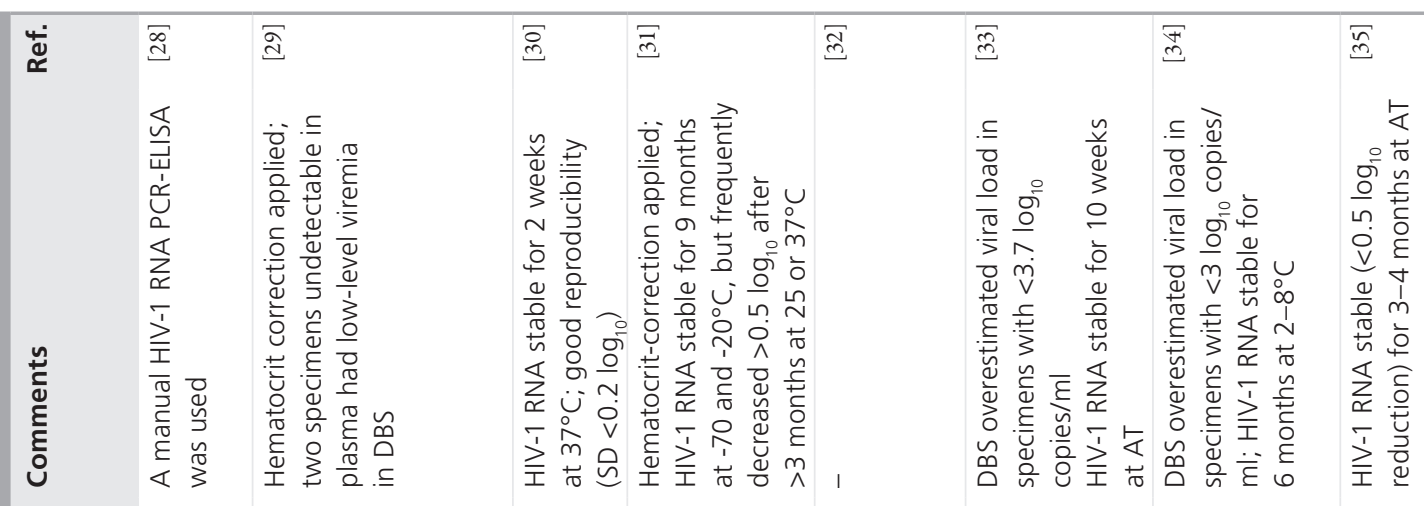

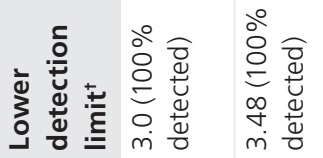

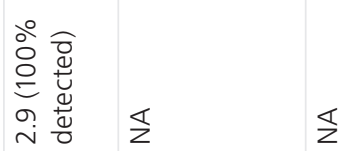

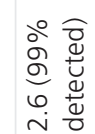

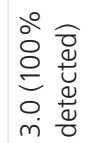

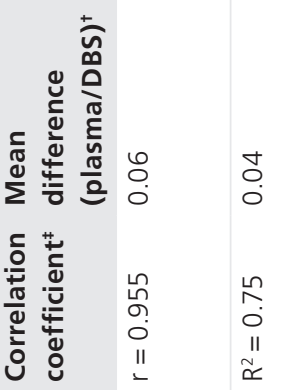

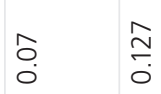

$\stackrel{8}{\square} \quad \mathbb{1}$

¿.

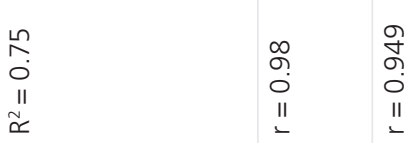

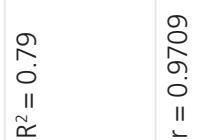

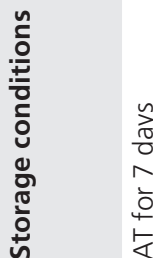

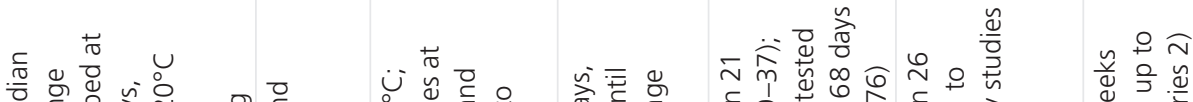

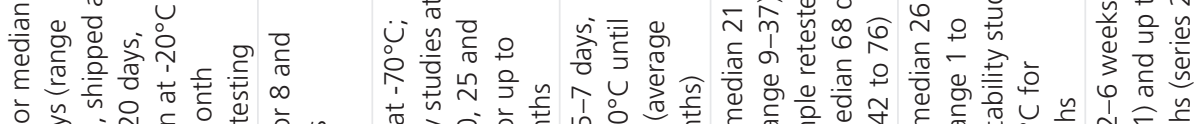

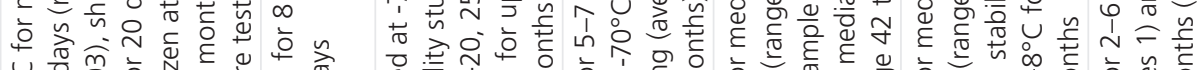

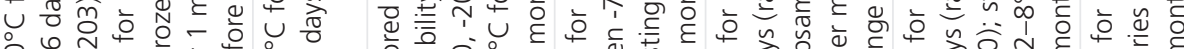

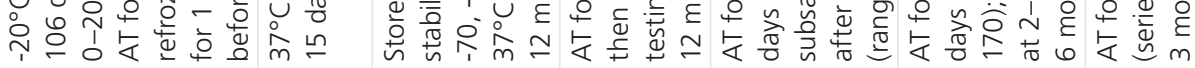

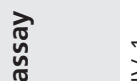

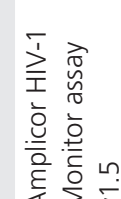

忿

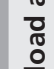

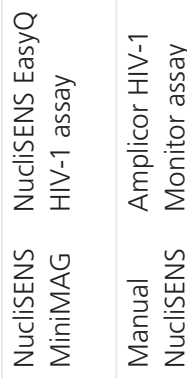

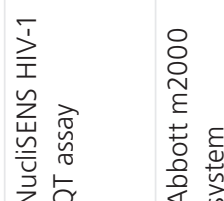

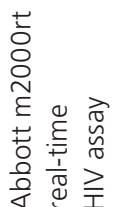

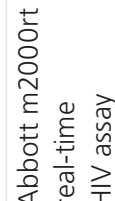

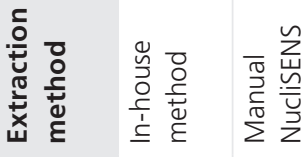

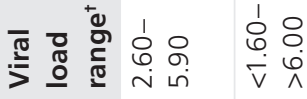

òㅇํำ

焉兽

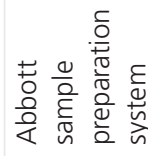

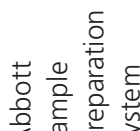

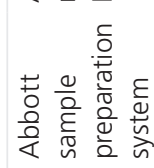

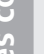

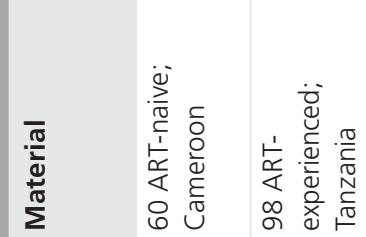

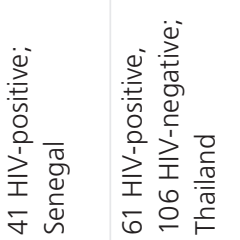

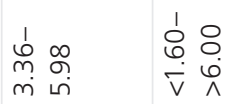

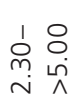

它

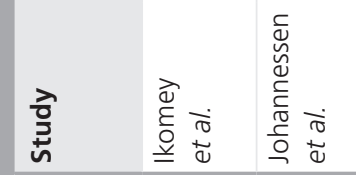

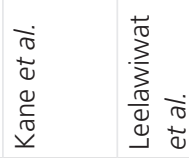

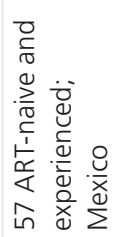

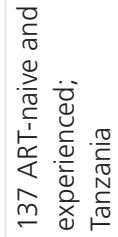

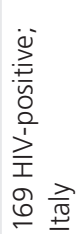

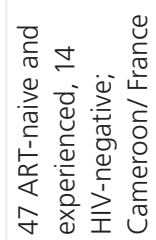

Dे
$+\frac{1}{0}$
$\frac{0}{0}$
$\frac{0}{2}$ 


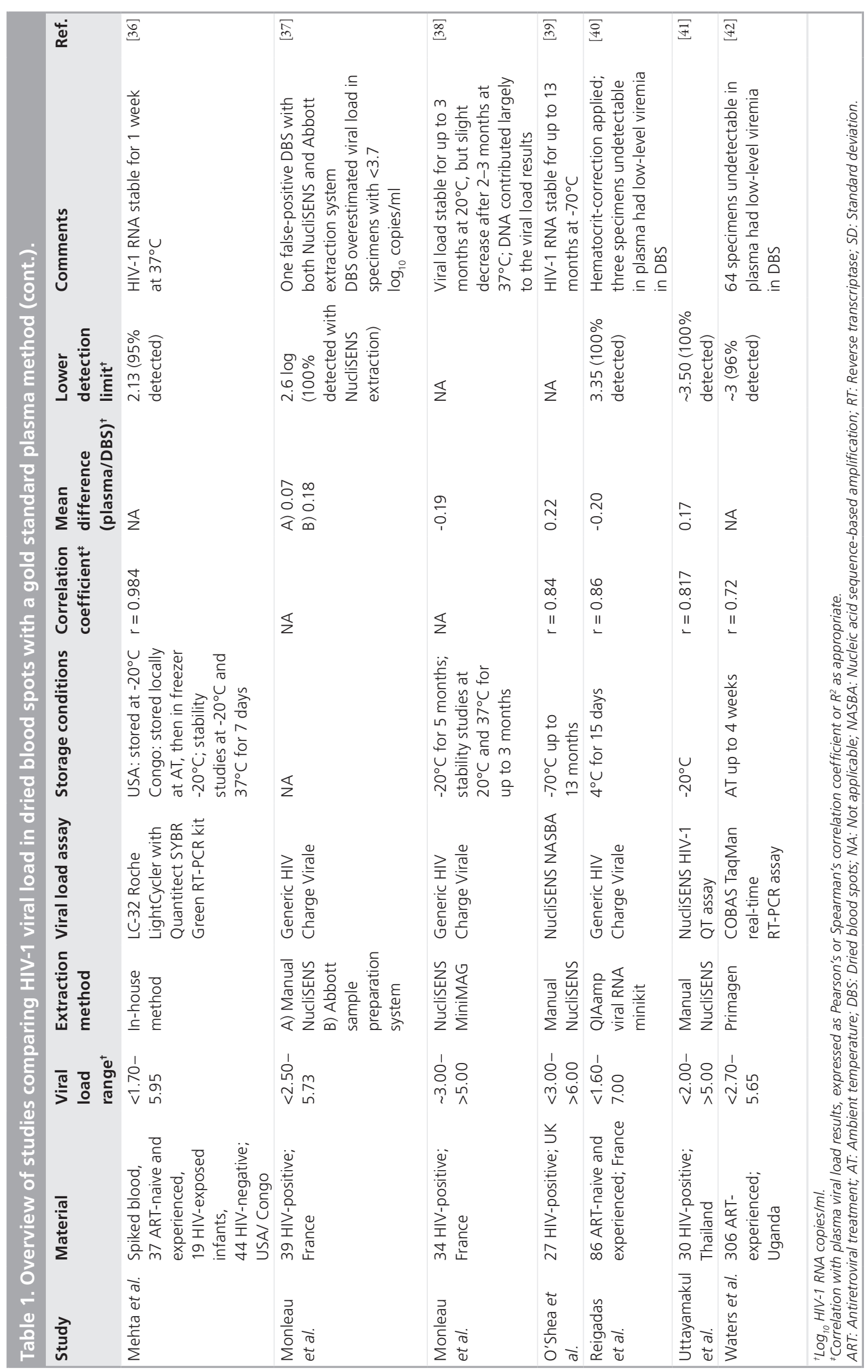




\section{Key terms}

Proviral DNA: HIV-I DNA integrated into the host cell's genome after reverse transcription from HIV-I RNA.

RT-PCR: Reverse transcription from RNA to complementary DNA followed by amplification by PCR.

NASBA: Nucleic acid sequence-based amplification. Specific amplification of RNA (and not DNA). filter paper cards (Whatman, Maidstone, UK; previously Schleicher \& Schuell, Keene, NH, USA). One study also evaluated IsoCode filter paper (Schleicher \& Schuell), and found a good correlation with plasma viral load results [26].

Some studies corrected for hematocrit when calculating the amount of plasma per blood spot, but found that the use of a constant correction factor based on the population's mean hematocrit produced very similar results to the use of actual hematocrit $[26,29,31,40]$. This is in accordance with a previous study reporting that the amount of plasma in each blood spot differed by less than $10 \%$ when hematocrit ranged from 30 to $50 \%$ [18]. Hence, the use of a constant correction factor seems appropriate when hematocrits are unavailable.

\section{- Extraction method}

Most studies used the NucliSENS ${ }^{\circledR}$ Isolation kit (BioMérieux, Inc., Marcy l'Etoile, France), or any of its precursors, to extract and isolate nucleic acids from DBS. The NucliSENS kit is based on the use of silica particles, as described by Boom and colleagues [43]. Other modified commercial kits or in-house extraction methods have also been employed (TABLE I).

An important study by Monleau and colleagues compared four different manual RNA extraction methods from dried plasma spots for HIV-1 viral-load quantification [37]. The NucliSENS kit was the most accurate and sensitive, followed by the Sample preparation system (Abbott Laboratories, Abbott Park, IL, USA). On the other hand, the QIAamp ${ }^{\circledR}$ viral RNA minikit (Qiagen, Valencia, CA, USA) and the High Pure Viral Nucleic Acid Kit (Roche Applied Science, IN, USA) significantly underestimated the HIV-1 RNA level or failed to yield a result. Although this study used dried plasma spots rather than DBS, the findings suggest that the extraction method is a critical factor in obtaining reliable results from dried spots. A recent study by Andreaotti and colleagues came to the same conclusion: extraction from DBS with the High Pure viral nucleic acid kit grossly underestimated viral load, while the NucliSENS kit, on the contrary, yielded excellent results [22].

\section{- Viral load assay}

Different commercial viral load kits have been assessed in conjunction with DBS (TABLE I). Although all kits were able to enumerate HIV-1 RNA, certain differences might exist with regard to precision and sensitivity.
Two studies have provided a comparison of different viral load assays. In a multicenter study, Brambilla and colleagues found that the NucliSENS HIV-1 QT assay (BioMérieux) gave more consistent results than the Amplicor HIV-1 Monitor assay (Roche Diagnostics, Branchburg, NJ, USA) [24]. More recently, Garrido and colleagues reported that the NucliSENS EasyQ HIV-1 kit (BioMérieux) yielded a higher precision and sensitivity than the m2000rt realtime HIV-1 kit (Abbott Laboratories) [27]. Furthermore, m2000rt underestimated HIV-1 RNA levels on average by $0.76 \log _{10}$ copies/ $\mathrm{ml}$, compared with $0.3 \log _{10}$ copies $/ \mathrm{ml}$ for NucliSENS. It is not clear, however, whether the differences observed in these two studies can be attributed to the extraction method, the viral load assay, or both.

\section{- Contribution of cell-associated proviral DNA}

Some studies have reported an overestimation of HIV-1 RNA levels in DBS from patients with low-level viremia $\left(<3.70 \log _{10}\right.$ copies $/ \mathrm{ml}$ in plasma). This phenomenon was observed in two studies using the Generic HIV Charge Virale assay (Biocentric, Bandol, France) [37,40], two studies using the m2000rt real-time HIV-1 assay (Abbott Laboratories) [33,34], and one study using the COBAS ${ }^{\circledR} \mathrm{TaqMan}^{\circledR}$ real-time reverse transcriptase (RT)-PCR assay (Roche Diagnostics) [42].

One explanation could be the contribution of HIV-1 proviral DNA from peripheral blood mononuclear cells (PBMC) in the amplification process. Most commercial viral load assays, including those used in the five studies above, are based on RT-PCR, which amplifies all nucleic acid material in the sample. Thus, a positive amplification result when whole blood specimens, such as DBS, are used instead of cell-free plasma could be caused by either RNA or DNA or both. The contribution of proviral DNA to the viral load result was recently confirmed by Monleau and colleagues, using the Generic HIV Charge Virale assay: DBS treated with DNase yielded significantly lower viral loads than DBS tested in the absence of DNase [38]. However, the presence of HIV-1 DNA in a patient sample does not imply treatment failure, and joint amplification of RNA and DNA can lead to serious problems in the interpretation of a positive result.

By contrast, nine studies using the NucliSENS assay did not report overestimation of HIV-1 RNA levels. NucliSENS is based on nucleic acid 
sequence-based amplification (NASBA), which is an isothermal amplification $\left(41^{\circ} \mathrm{C}\right)$ designed to specifically amplify single-stranded RNA by the use of T7 RNA polymerase. In the absence of heat denaturation, double-stranded DNA cannot participate in the amplification process $[44,45]$. NASBA technology, therefore, appears to be particularly suitable when DBS are used instead of cell-free plasma for HIV-1 RNA quantification.

\section{- Lower detection limit}

The sensitivity of commercial viral load assays has improved substantially over the past decade. Whereas older assays typically had a detection limit of 2.6-2.7 $\log _{10}$ copies $/ \mathrm{ml}$, the new generation assays can reliably quantify HIV-1 RNA down to $1.3-1.7 \log _{10}$ copies $/ \mathrm{ml}$. These ultrasensitive assays usually require an input volume of approximately $1 \mathrm{ml}$ of plasma, equivalent to $2.5 \mathrm{ml}$ of whole blood.

Dried blood spots consist of small volumes of whole blood; each circle of a 903 filter paper card holds $75-80 \mu \mathrm{l}$ of whole blood when saturated [102]. The input volume to the nucleic acid amplification, therefore, is markedly reduced when DBS are used rather than plasma. Therefore, DBS-based HIV-1 RNA quantification cannot achieve the same sensitivity as standard plasmabased methods. Most DBS studies have reported a lower detection limit around $3 \log _{10}$ copies $/ \mathrm{ml}$, ranging from 2.13 [36] to $3.72 \log _{10}$ copies $/ \mathrm{ml}$ [27].

In clinical practice, viral load is measured to detect treatment failure and assess the need for second-line treatment. Guidelines for North America and Europe define treatment failure as any sustained detectable viremia $[8,9]$. However, since standard genotypic resistance assays have low success rates in specimens with viral loads below 2.7-3.0 $\log _{10}$ copies $/ \mathrm{ml}[46]$, many clinicians prefer to delay treatment modification until viral load exceeds this level and a resistance profile is available. In resource-limited settings, where the selection of second-line antiretroviral drugs is scarce, WHO recommends to conserve first-line treatment as long as viral load does not exceed $3.7 \log _{10}$ copies $/ \mathrm{ml}$, because the risk of clinical progression is limited below this level $[12,13]$. In South Africa, home to the world's largest ART program, switching to second-line treatment is recommended in patients with a sustained viral load above $3.7 \log _{10}$ copies $/ \mathrm{ml}$, despite stepped-up adherence support [47].

Thus, a detection limit around $3 \log _{10}$ copies $/ \mathrm{ml}$, as observed in several DBS studies, although not sufficiently sensitive to be used with the North American and European guidelines, would be sufficiently sensitive in combination with the WHO guidelines or South African policy to decide who needs regimen switching in resource-limited settings.

\section{- Storage of DBS in the field for viral load quantification}

Several studies have investigated how storage of DBS affects HIV-1 RNA stability. Fiscus and colleagues found some loss of HIV-1 RNA (0.0261 $\log _{10}$ copies $/ \mathrm{ml}$ per day) with storage at room temperature over a 28-day period using IsoCode filter paper [26], and Alvarez-Muñoz and colleagues observed a $0.53 \log _{10}$ copies/ $\mathrm{ml}$ decrease in viral load after only 7 days storage at $37^{\circ} \mathrm{C}$ [21]. Furthermore, a recent study from Thailand found that HIV-1 RNA levels frequently decreased by more than 0.5 $\log _{10}$ copies $/ \mathrm{ml}$ in samples stored for more than 3 months at room temperature or $37^{\circ} \mathrm{C}[31]$. One study suggested (although with dried plasma and not DBS) that most of the RNA loss during storage occurred in the actual drying step [48].

By contrast, two recent field studies from Tanzania and Cameroon reported no statistically significant HIV-1 RNA decline in DBS stored at room temperature for 10 weeks [33] and 3-4 months [35], and a study from Senegal found stable HIV-1 RNA levels in DBS stored at $37^{\circ} \mathrm{C}$ for 14 days [30]. Moreover, in a multicenter study from North America, there was no decrease in viral load after 1 year of storage at room temperature [24], and a recent study from Italy found that HIV-1 RNA was stable in DBS stored at $2-8^{\circ} \mathrm{C}$ for 6 months [34]. An important study by van Deursen and colleagues evaluated a number of different storage conditions, and found stable HIV-1 RNA levels (less than $0.3 \log _{10}$ copies $/ \mathrm{ml}$ change) in DBS stored for 9 months at room temperature, 9 weeks at $37^{\circ} \mathrm{C} / 40 \%$ humidity and 3 weeks at $37^{\circ} \mathrm{C} / 80 \%$ humidity, suggesting that humidity might be particularly detrimental to HIV-1 RNA stability [25]. Monleau and colleagues found stable viral load levels after 3 months at $20^{\circ} \mathrm{C}$ and 1 month at $37^{\circ} \mathrm{C} /$ high humidity, but a slight decline after $2-3$ months at $37^{\circ} \mathrm{C} /$ high humidity [38]. Three studies assessed long-term storage at $-70^{\circ} \mathrm{C}$, and found that HIV-1 RNA levels were stable for at least 1 year [24,31,39].

Taken together, these studies indicate that HIV-1 RNA is relatively stable during storage, as long as extreme environmental conditions can be avoided $\left(37^{\circ} \mathrm{C}\right.$ and $/$ or high humidity). During 


\section{Key term}

RT-nested PCR: The product of the primary RT-PCR reaction is used as a template for a secondary round of PCR amplification. storage in the field, high temperatures and direct sunlight should be avoided, and DBS specimens should always be stored in closed plastic bags with desiccant sachets to control humidity. For clinical monitoring of patients on ART, monthly shipment of DBS to a reference laboratory would probably be appropriate, both to avoid degradation of HIV-1 RNA, and to assure a timely switch to second-line ART in case of treatment failure. In extreme climates, with high humidity and temperatures constantly at $37^{\circ} \mathrm{C}$ and above, more frequent shipment might be necessary. If longterm storage is required, for example for research purposes, samples should be stored frozen.

\section{HIV-I genotypic resistance testing on DBS}

Over the past few years, several studies have evaluated the use of DBS for HIV-1 genotypic resistance testing [32,38,49-59]. TABLE 2 gives an overview of studies comparing DBS-derived genotypes with those of a gold standard plasma method.

Anticoagulated whole blood obtained by venipuncture was used to prepare the dried spots. The input volume per spot was either $50 \mu$, $100 \mu$ or unspecified. DBS specimens were air dried from 1 to $24 \mathrm{~h}$, usually overnight. All used 903 filter paper cards (Whatman; previously Schleicher \& Schuell); however, two studies also evaluated the performance of FTA Elute Paper (Whatman), and found that it was inferior to 903 filter paper [50,53].

\section{- Extraction method}

Most studies used a manual Boom technique to extract and isolate nucleic acids from DBS [43], mainly by the use of the NucliSENS kit, although a few used other commercial assays with some modifications (TABLE 2).

As for viral load quantification, Monleau and colleagues found that genotyping was efficient after extraction with the NucliSENS kit and the Sample preparation system, whereas the QIAamp viral RNA minikit and the High Pure viral nucleic acid kit frequently failed to yield a result; however, this study used dried plasma spots rather than DBS [37]. By contrast, Hearps and colleagues recently reported that amplification efficiency from DBS was equivalent after extraction with the NucliSENS kit and the High Pure viral nucleic acid kit [53]. The latter study modified the High Pure extraction protocol to include incubating the DBS in water prior to extraction, and found this to be crucial.

\section{Resistance genotyping assay}

Different resistance genotyping assays have been assessed in conjunction with DBS (TABLE 2). In general, in-house RT-nested PCR assays appear to be more efficient than commercial assays when DBS are used instead of plasma. Amplification success rates with the in-house assays ranged from $83-100 \%$, compared with $38.6-83.3 \%$ for the ViroSeq HIV-1 genotyping system (Abbott Molecular, IL, USA), and $78.8 \%$ for the TruGene ${ }^{\circledR}$ HIV-1 genotyping assay (Siemens Healthcare Diagnostics, IL, USA).

Amplification efficiency was reduced in DBS specimens with low viral loads. Hallack and colleagues found that $90 \%$ of DBS with a viral load above 6000 copies $/ \mathrm{ml}$ were successfully genotyped, compared with $58 \%$ of DBS with a viral load below 6000 copies $/ \mathrm{ml}$, using the TruGene assay [52]. In a recent study from Mexico using the ViroSeq assay, Lira and colleagues successfully genotyped $60 \%$ of DBS with viral loads above 14,000 copies $/ \mathrm{ml}$, but none of the DBS with viral loads below this level [32]. Furthermore, Youngpairoj and colleagues reported that only $8 \%$ of DBS could be genotyped when viral load was below 10,000 copies $/ \mathrm{ml}$, compared with $81 \%$ when viral load was above 10,000 copies $/ \mathrm{ml}$, using the ViroSeq assay [58]. In the latter study, however, the DBS were re-tested with an in-house RT-nested PCR assay, which successfully genotyped $95 \%$ of the samples. Thus, although commercial kits are efficient in samples with high-level viremia, such as untreated individuals, in-house RT-nested PCR assays appear to be more sensitive in samples with low-level viremia, such as patients with early treatment failure.

\section{- Comparison of genotypes in DBS \& plasma}

Most studies reported a high concordance between nucleotide sequences derived from DBS and plasma (TABLE 2). Nucleotide similarity between the two sample types ranged from 98.1 to $99.9 \%$. Drug-resistant mutations found in plasma were detected in $82-100 \%$ of the corresponding DBS specimens. Few additional mutations were detected in DBS, and those found were mainly as amino acid mixtures with the wild-type strain.

A total of two studies reported a significant discrepancy between genotypes derived from DBS and plasma. Buckton and colleagues observed several amino acid differences in paired plasma and DBS specimens [50]. However, the sample size was small $(\mathrm{n}=12)$, and only two patients had clinically significant drug resistance; in both cases 


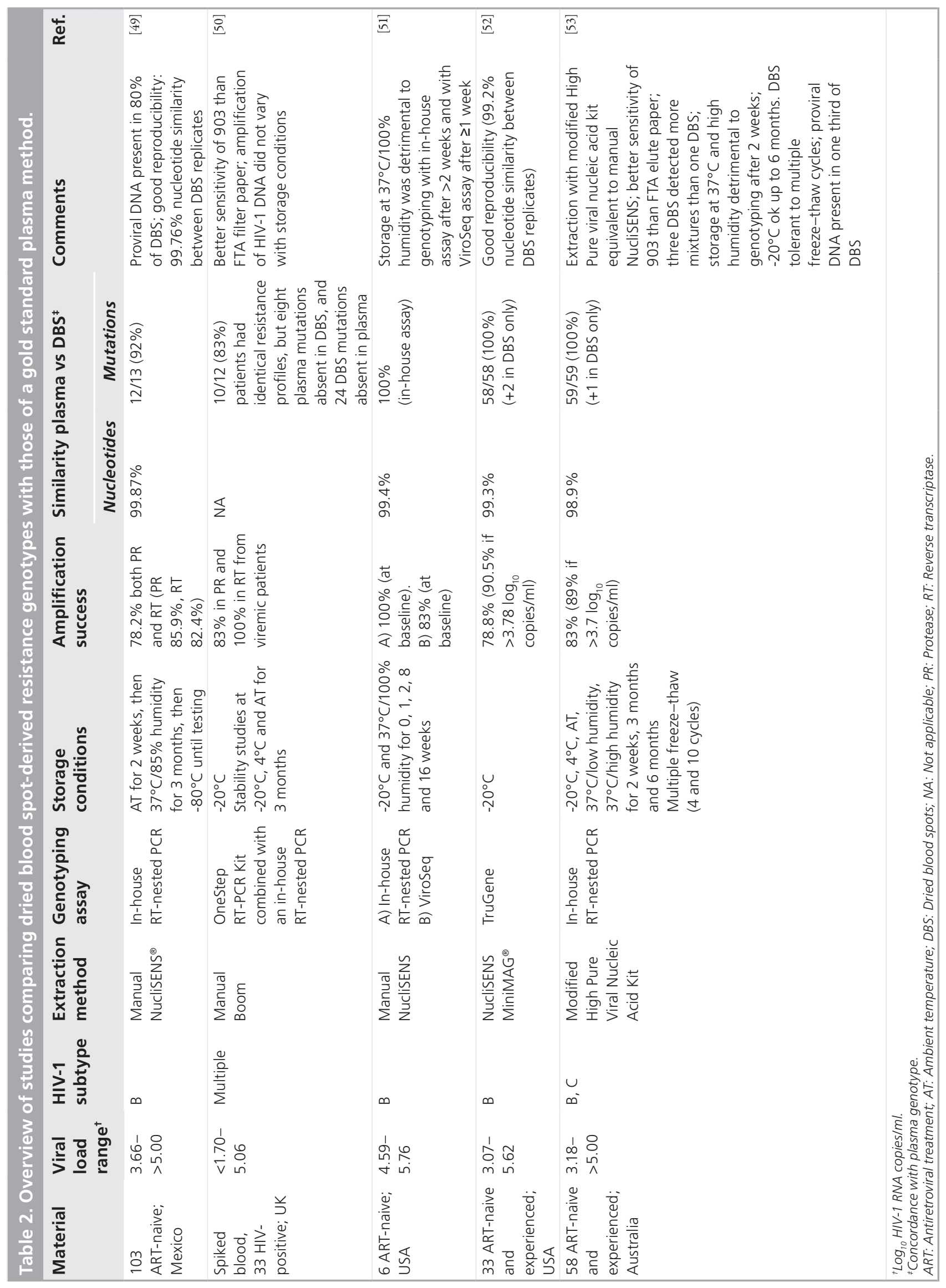




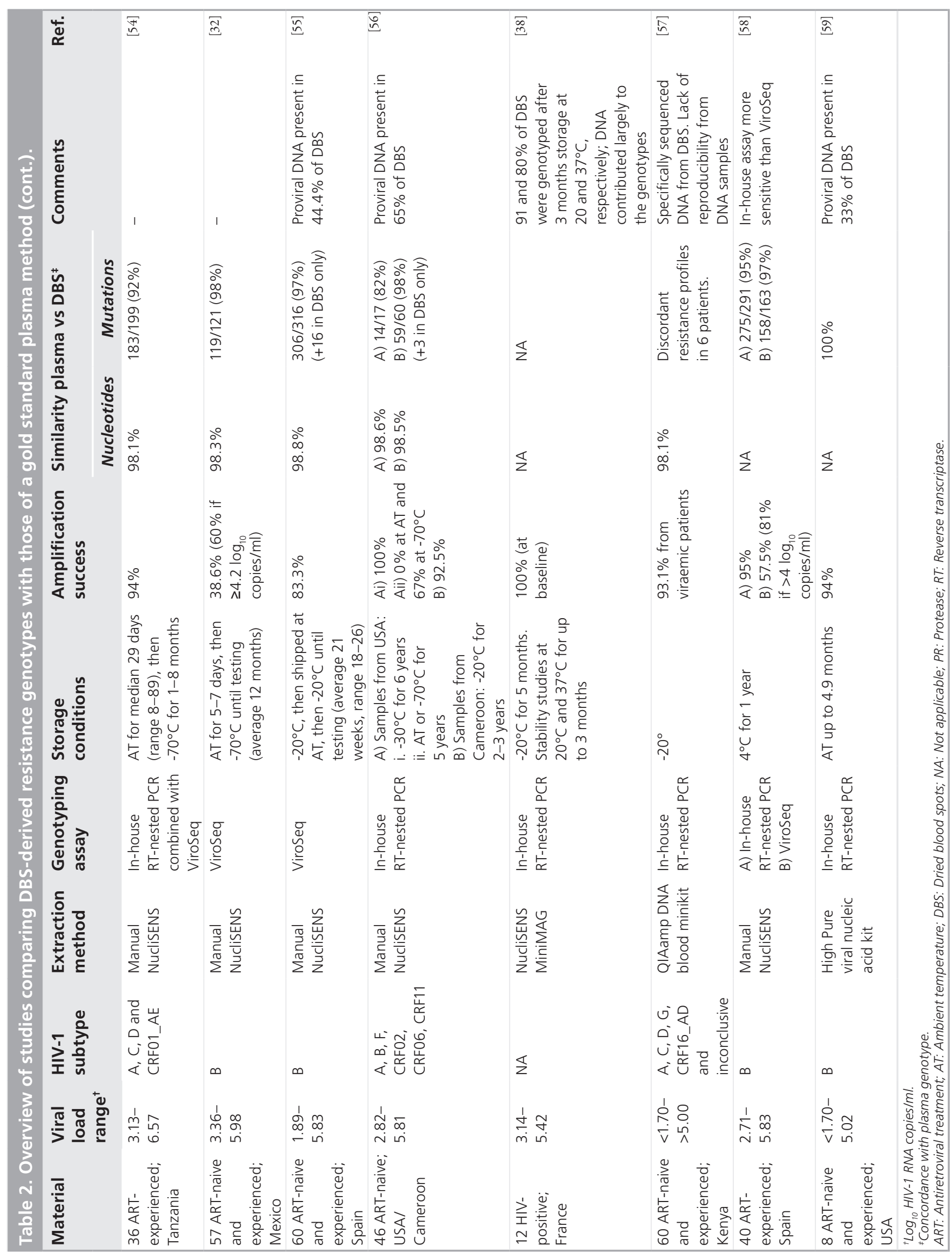


the plasma and DBS genotypes were discordant. In addition, Steegen and colleagues reported a lack of reproducibility for the detection of drugresistant mutations in DBS, but this study specifically sequenced DNA and can not be compared directly to other studies that include an RT-PCR step [57]. By contrast, two studies reported a high degree of reproducibility from DBS specimens, with a mean nucleotide sequence concordance of $99.2 \%$ and $99.76 \%$ for the set of DBS replicates, using the commercial TruGene assay and an in-house assay, respectively [49,52].

\section{- Interference of cell-associated proviral DNA}

Dried blood spots consist of whole blood, and cell-associated HIV-1 DNA from PMBC can be present in the nucleic acid sample. Some studies amplified DBS extracts in the absence of reverse transcriptase to assess whether proviral DNA contributed significantly to the amplification product $[49,53,55,56,59]$. In these studies, the presence of proviral DNA was demonstrated in 33-80\% of RT-PCR-positive DBS samples. Despite the presence of proviral DNA, however, these studies reported a high concordance between plasma- and DBS-derived sequences.

Recently, Monleau and colleagues reported that amplification efficiency from DBS was markedly reduced in samples treated with DNase, confirming that proviral DNA contributes significantly to the genotypes derived from DBS [38]. Of note, this study found that the relative contribution of DNA appeared to increase with duration of DBS storage, indicating that RNA might be degraded at a faster rate than DNA).

The interference of proviral DNA may vary according to treatment status and viral load level. In patients who fail treatment, more drug-resistant mutations tend to be detectable in plasma than in PBMC, particularly when viral burden is low $[60,61]$. On the contrary, in patients who interrupt treatment, proviral DNA in PBMC can act as an archive of resistance mutations, and DBS might provide more information than plasma in such patients [61]. However, the clinical relevance of treatment status and viral load level when DBS are used to genotype HIV-1 remains to be determined.

\section{Storage of DBS in the field for}

\section{genotypic-resistance testing}

Several studies have investigated how storage conditions influence the ability to genotype HIV-1 from DBS. Youngpairoj and colleagues found that $95 \%$ of DBS specimens could be genotyped after storage at $4^{\circ} \mathrm{C}$ for 1 year [58], whereas Ziemniak and colleagues successfully genotyped all 16 viraemic DBS specimens stored at room temperature for up to 4.9 months [59]. Other studies have reported high amplification success rates after storage at $20^{\circ} \mathrm{C}$ for 3 months [38], at tropical room temperature for up to 3 months [54], and at $37^{\circ} \mathrm{C} / 85 \%$ humidity for 3 months [49]. Two studies evaluated DBS stored long-term, and reported successful amplification of most specimens stored at $-20^{\circ} \mathrm{C}$ or at $-70^{\circ} \mathrm{C}$ for $5-6$ years [56], and two thirds of specimens stored ambiently for 3-6 years [62].

On the contrary, Garcia-Lerma and colleagues reported that storage at extreme conditions $\left(37^{\circ} \mathrm{C} / 100 \%\right.$ humidity) severely compromised amplification already after 2 weeks [51]. Furthermore, in a study by Garrido and colleagues, only half of viremic DBS specimens could be genotyped after storage at $4^{\circ} \mathrm{C}$ in the absence of desiccant bags, underscoring the importance of adequate humidity control [63]. A recent study by Hearps and colleagues investigated various storage conditions and found limited amplification success rates after storage 2 weeks at $37^{\circ} \mathrm{C} / 90 \%$ humidity, but better results after storage at $37^{\circ} \mathrm{C} /$ below $20 \%$ humidity, confirming that humidity is a hazard for DBS stability [53]. In the latter study, only storage at $-20^{\circ} \mathrm{C}$ or at $4^{\circ} \mathrm{C}$ was associated with $100 \%$ amplification success after 2 weeks, compared with $75 \%$ in samples stored at ambient temperature (average $22.1^{\circ} \mathrm{C}$ ). Moreover, the effect of repeated freeze-thaw cycles was assessed, and it was found that the majority of DBS specimens were amplifiable after four and ten freeze-thaw cycles.

Taken together, these studies indicate that genotyping of DBS might be more sensitive to suboptimal storage conditions than viral load quantification. Genotyping assays usually rely on the amplification of larger HIV-1 pol fragments, which may be more vulnerable to degradation during storage. In practice, storage at $-20^{\circ} \mathrm{C}$ may not be available in rural resource-limited settings; however, even rural clinics often participate in the national vaccination program and might have access to a refrigerator. If possible, DBS should be stored in a refrigerator at the collection site and specimens should always be stored in closed plastic bags with desiccant sachets to control humidity. The WHO, in collaboration with a network of international experts (HIVResNet), recently published a laboratory strategy for surveillance of 
transmitted HIV drug resistance, where the use of DBS was recommended in resource-limited settings [64]. Herein, it is recommended to store DBS at room temperature for a maximum period of 2 weeks before transport to the reference laboratory. If long-term storage is required, for example for research purposes, samples should be stored at less than or equal to $-20^{\circ} \mathrm{C}$ in the original unopened ziplock bags with desiccant. The WHO method using DBS has been successfully employed in surveys of transmitted drug resistance in Malawi, Tanzania, Iran and China [65-68].

\section{Other possible applications of DBS}

The use of DBS has been evaluated for a number of other HIV-related analyses, such as detection of HIV-1 antibodies (used to diagnose HIV infection) [69], and CD4-cell count enumeration (used to determine treatment eligibility in HIV patients) [70]. However, several rapid antibody tests are on the market, and low-tech point-of-care assays for CD4-cell counts are in the pipeline, rendering DBS a second choice for these purposes.

Therapeutic drug monitoring (TDM) of antiretroviral drugs is not mandatory in patients who receive ART, but may be useful in patients with potential drug-drug interactions, suspected poor adherence, comorbidities, or in pregnant women and children $[8,9]$. A few studies have assessed the use of DBS for TDM and reported that DBS yield accurate and reproducible results [71,72]. Although this test is currently restricted to research purposes in resource-limited settings, TDM might play a role in the clinical management of selected problem patients in the future.

\section{Future perspective}

Some challenges still remain in the application of DBS techniques in HIV monitoring (Box I). Viral load quantification using DBS, as a routine test at regular intervals or in selected patients with suspected treatment failure, will have to be standardized and optimized for a highthroughput setting. Excision of blood spots and extraction of nucleic acids from DBS samples requires more hands-on time than automated systems designed for plasma samples, and carries the risk of cross-contamination. Although certain studies have explored simplified laboratory procedures, such as the use of a hand-held office hole-punch for excision of blood spots [73], there is a need for increased automation of the excision and extraction step to allow for mass testing in high-prevalence settings. Furthermore, standardization of viral load assays for DBS usage is required, and it should be ascertained whether there are significant differences between PCRbased and NASBA-based assays in patients with low-level viremia.

With regard to drug-resistance testing, most studies have utilized in-house assays for genotyping from DBS, and there is a need for standardization and quality control of the protocols used by different laboratories. The WHO has developed recommendations for the use of DBS in surveillance of transmitted HIV drug resistance, and these can serve as a guide for the use of DBS in clinical patient management [64]. However, further research is warranted to explore the interference of proviral DNA according to treatment status and viral load level, as some studies have indicated possible differences between plasma and DBS in early treatment failure and in patients who interrupt treatment $[60,61]$.

The ideal solution for virological monitoring in resource-limited settings would be a simple, stable, robust and affordable point-of-care assay, both for HIV-1 RNA viral-load quantification and drug-resistance testing. This would remove the difficulties related to transport of samples and reporting back results, and facilitate immediate treatment decisions at the testing site. However, field-adapted tools for virological monitoring do not exist. A semi-quantitative

Box 1. Unresolved issues and priorities for research.

\footnotetext{
- Optimize excision and extraction from dried blood spots (DBS) for a high-throughput setting.

- Determine whether there are significant differences between PCR-based and nucleic acid sequence-based amplification viral load assays.

- Standardize viral load and resistance assays for DBS usage.

- Explore the interference of proviral DNA on the genotypes of patients at various treatment stages and with different viral load levels.

- Develop user-friendly guidelines for the use of DBS in viral load quantification and drug-resistance testing.
} 
dipstick HIV-1 RNA assay is under development by a research group at Cambridge University, but this assay is not yet commercially available [74]. Other efforts to develop point-of-care assays are still far from materializing into available products. Thus, for the coming years, DBS appear to be the only viable option for viral load quantification and resistance testing in settings with limited laboratory capacity.

\section{Financial \& competing interests disclosure}

The author has no relevant affliations or financial involvement with any organization or entity with a financial interest in or financial conflict with the subject matter or materials discussed in the manuscript. This includes employment, consultancies, honoraria, stock ownership or options, expert testimony, grants or patents received or pending, or royalties. No writing assistance was utilized in the production of this manuscript.

\section{Executive summary}

\section{Scale-up of antiretroviral treatment in resource-limited settings}

- Antiretroviral treatment has radically changed the prognosis for people living with HIVIAIDS.

- More than 4 million people are receiving antiretroviral treatment in low- and middle-income countries.

\section{Monitoring of antiretroviral treatment}

- In high-income countries, monitoring of antiretroviral treatment with viral load measurements and resistance testing is the standard of care.

- In resource-limited settings, these tests are rarely available due to their costs, complexity and stringent requirements for storage and transport of plasma.

- Consequently, treatment failure is not detected until the patients develop severe immunodeficiency, at which stage widespread resistance is likely.

\section{Current use of dried blood spots in resource-limited settings}

- Recently, several African countries started to use dried blood spots (DBS) to screen for HIV in infants born of HIV-infected mothers.

- Infant screening programs can serve as a model for further expansion of DBS monitoring strategies in resource-limited settings.

HIV-1 viral load quantification using DBS

- Dried-blood spots and plasma viral load results correlate well.

- The lower detection limit for DBS is around $3 \log _{10}$ copies $/ \mathrm{ml}$.

- Manual Boom extraction combined with the NucliSENS ${ }^{\circledR}$ assay (BioMérieux) has been most widely documented.

- Interference of cell-associated HIV-1 proviral DNA may be overcome by the use of Nucleic acid sequence-based amplification rather than PCR-based assays.

\section{HIV-1 genotypic resistance testing on DBS}

- There is a high concordance between nucleotide sequences derived from DBS and plasma.

- In-house RT-nested PCR assays appear to be more efficient than commercial assays.

- HIV-1 proviral DNA is present in 33-80\% of DBS samples, but the clinical relevance of this is uncertain.

\section{Storage of DBS in the field}

- DBS can be stored and shipped at ambient temperature, but high temperatures and/or humidity should be avoided.

- For monitoring of viral load in patients on ART, monthly shipment of DBS to a reference laboratory seems appropriate.

- Genotyping of DBS is more sensitive to suboptimal storage conditions, and a maximum storage period of 2 weeks at ambient temperature is recommended.

\section{Future perspective}

- DBS techniques for viral load quantification and resistance genotyping have to be standardized and optimized for a high-throughput setting.

- The ideal option for virological monitoring in resource-limited settings would be a simple, stable, robust and affordable point-of-care assay.

\section{Bibliography}

Papers of special note have been highlighted as: - of interest

- of considerable interest

1 Joint United Nations Program on HIV/AIDS (UNAIDS), World Health Organization (WHO). AIDS Epidemic Update: December 2009. UNAIDS, Geneva, Switzerland (2009).
2 Zwahlen M, Harris R, May M et al. Mortality 4 of HIV-infected patients starting potent antiretroviral therapy: comparison with the general population in nine industrialized countries. Int. J. Epidemiol. 38(6), 1624-1633 (2009).

3 World Health Organization (WHO). Towards universal access. Scaling up priority HIV/AIDS interventions in the health sector. Progress report 2009. WHO, Geneva, Switzerland (2009).
Bussmann H, Wester CW, Ndwapi N et al. Five-year outcomes of initial patients treated in Botswana's National Antiretroviral Treatment Program. AIDS 22(17), 2303-2311 (2008).

5 Nash D, Katyal M, Brinkhof MW et al. Long-term immunologic response to antiretroviral therapy in low-income countries: a collaborative analysis of prospective studies. AIDS 22(17), 2291-2302 (2008). 
6 Lawn SD, Myer L, Orrell C, Bekker LG, Wood R. Early mortality among adults accessing a community-based antiretroviral service in South Africa: implications for programme design. AIDS 19(18), 2141-2148 (2005).

7 Palombi L, Marazzi MC, Voetberg A, Magid NA) Treatment acceleration program and the experience of the DREAM program in prevention of mother-to-child transmission of HIV. AIDS 21(Suppl 4), S65-S71 (2007).

8 Hammer SM, Eron JJ Jr, Reiss P et al. Antiretroviral treatment of adult HIV infection: 2008 recommendations of the International AIDS Society - USA panel. JAMA 300 (5), 555-570 (2008).

9 European AIDS Clinical Society (EACS). Guidelines for the clinical management and treatment of HIV infected adults in Europe. EACS, Paris, France (2009).

10 Cozzi-Lepri A, Phillips AN, Ruiz L et al. Evolution of drug resistance in HIV-infected patients remaining on a virologically failing combination antiretroviral therapy regimen. AIDS 21(6), 721-732 (2007).

11 Lundgren JD, Babiker A, El-Sadr W et al. Inferior clinical outcome of the $\mathrm{CD}^{+}$ cell count-guided antiretroviral treatment interruption strategy in the SMART study: role of $\mathrm{CD} 4^{+}$cell counts and HIV RNA levels during follow-up. J. Infect. Dis. 197(8), 1145-1155 (2008).

12 World Health Organization (WHO). Antiretroviral therapy for HIV infection in adults and adolescents: recommendations for a public health approach. 2006 revision. WHO, Geneva, Switzerland (2006).

13 World Health Organization (WHO). Rapid advice: antiretroviral therapy for HIV infection in adults and adolescents. WHO, Geneva, Switzerland (2009).

14 Mee P, Fielding KL, Charalambous S, Churchyard GJ, Grant AD. Evaluation of the WHO criteria for antiretroviral treatment failure among adults in South AfricA) AIDS 22(15), 1971-1977 (2008).

15 van Oosterhout JJ, Brown L, Weigel R et al. Diagnosis of antiretroviral therapy failure in Malawi: poor performance of clinical and immunological WHO criteriA) Trop. Med. Int. Health 14(8), 856-861 (2009).

16 Hosseinipour MC, van Oosterhout JJ, Weigel R et al. The public health approach to identify antiretroviral therapy failure: high-level nucleoside reverse transcriptase inhibitor resistance among Malawians failing first-line antiretroviral therapy. AIDS 23(9), 1127-1134 (2009).
17 Rawizza H, Chaplin B, Rao T et al. Comparison of immunological and virological failure criteria in a large ART program in NigeriA) Presented at: $17^{\text {h }}$ Conference on Retroviruses and Opportunistic Infections. San Francisco, CA, USA, 16-19 February 2010.

18 Mei JV, Alexander JR, Adam BW, Hannon WH. Use of filter paper for the collection and analysis of human whole-blood specimens. J. Nutr. 131(5), 1631S-1636S (2001).

19 Sherman GG, Stevens G, Jones SA, Horsfield P, Stevens WS. Dried-blood spots improve access to HIV diagnosis and care for infants in low-resource settings. J. Acquir. Immune Defic. Syndr. 38(5), 615-617 (2005).

20 Violari A, Cotton MF, Gibb DM et al. Early antiretroviral therapy and mortality among HIV-infected infants. N. Engl. J. Med. 359 (21), 2233-2244 (2008).

21 Alvarez-Munoz M, Zaragoza-Rodriguez S, Rojas-Montes $\mathrm{O}$ et al. High correlation of human immunodeficiency virus type- 1 viral load measured in dried-blood spot samples and in plasma under different storage conditions. Arch. Med. Res. 36(4), 382-386 (2005).

22 Andreotti M, Pirillo M, Guidotti G et al. Correlation between HIV-1 viral load quantification in plasma, dried-blood spots and dried-plasma spots using the Roche COBAS Taqman assay. J. Clin. Virol. 47(1), 4-7 (2010).

23 Ayele W, Schuurman R, Messele T et al. Use of dried spots of whole-blood, plasma and mother's milk collected on filter paper for measurement of human immunodeficiency virus type 1 burden. J. Clin. Microbiol. 45(3), 891-896 (2007).

24 Brambilla D, Jennings C, Aldrovandi G et al. Multicenter evaluation of use of dried-blood and plasma-spot specimens in quantitative assays for human immunodeficiency virus RNA: measurement, precision, and RNA stability. J. Clin. Microbiol. 41(5), 1888-1893 (2003).

25 van Deursen P, Oosterlaken T, Andre P et al. Measuring human immunodeficiency virus type 1 RNA loads in dried-blood spot specimens using NucliSENS ${ }^{\circledR}$ EasyQ HIV-1 v2.0. J. Clin. Virol. 47(2), 120-125 (2010).

-. Comprehensive evaluation of storage conditions for viral load quantification.

26 Fiscus SA, Brambilla D, Grosso L, Schock J, Cronin M. Quantitation of human immunodeficiency virus type 1 RNA in plasma by using blood dried on filter paper. J. Clin. Microbiol. 36(1), 258-260 (1998).
27 Garrido C, Zahonero N, Corral A, Arredondo M, Soriano V, de Mendoza C. Correlation between human immunodeficiency virus type 1 (HIV-1) RNA measurements obtained with dried-blood spots and those obtained with plasma by use of NucliSENS ${ }^{\circledR}$ EasyQ HIV-1 and Abbott RealTime HIV load tests. J. Clin. Microbiol. 47(4), 1031-1036 (2009).

28 Ikomey GM, Atashili J, Okomo-Assoumou MC, Mesembe M, Ndumbe PM. Dried-blood spots versus plasma for the quantification of HIV-1 RNA using the manual (PCR-ELISA) amplicor monitor HIV-1 version 1.5 assay in Yaounde, Cameroon. J. Int. Assoc. Physicians AIDS Care (Chic Ill) 8(3), 181-184 (2009).

29 Johannessen A, Garrido C, Zahonero N et al. Dried-blood spots perform well in viral load monitoring of patients who receive antiretroviral treatment in rural Tanzania. Clin. Infect. Dis. 49(6), 976-981 (2009).

30 Kane CT, Ndiaye HD, Diallo S et al. Quantitation of HIV-1 RNA in dried-blood spots by the real-time NucliSENS ${ }^{\circledR}$ EasyQ HIV-1 assay in Senegal. J. Virol. Methods 148(1-2), 291-295 (2008).

31 Leelawiwat W, Young NL, Chaowanachan T et al. Dried-blood spots for the diagnosis and quantitation of HIV-1: stability studies and evaluation of sensitivity and specificity for the diagnosis of infant HIV-1 infection in Thailand. J. Virol. Methods 155(2), 109-117 (2009).

- Thorough evaluation of storage conditions for viral load quantification.

32 Lira R, Valdez-Salazar H, Vazquez-Rosales G et al. Genotypic testing for HIV-1 drug resistance using dried-blood samples. Arch. Virol. 155(7), 1117-1125 (2010).

33 Lofgren SM, Morrissey AB, Chevallier CC et al. Evaluation of a dried-blood spot HIV-1 RNA program for early-infant diagnosis and viral-load monitoring at rural and remote healthcare facilities. AIDS 23(18), 2459-2466 (2009).

- Field study demonstrating the programmatic efficiency of a dried blood spots (DBS) testing strategy in rural Tanzania.

34 Marconi A, Balestrieri M, Comastri G et al. Evaluation of the Abbott real-time HIV-1 quantitative assay with dried-blood spot specimens. Clin. Microbiol. Infect. 15(1), 93-97 (2009).

35 Mbida AD, Sosso S, Flori P et al. Measure of viral load by using the Abbott real-time HIV-1 assay on dried-blood and plasma spot specimens collected in 2 rural dispensaries in Cameroon. J. Acquir. Immune Defic. Syndr. 52(1), 9-16 (2009). 
36 Mehta N, Trzmielina S, Nonyane BA et al. Low-cost HIV-1 diagnosis and quantification in dried-blood spots by real time PCR. PLoS One 4(6), e5819 (2009).

37 Monleau M, Montavon C, Laurent C et al. Evaluation of different RNA extraction methods and storage conditions of dried plasma or blood spots for human immunodeficiency virus type 1 RNA quantification and PCR amplification for drug resistance testing. J. Clin. Microbiol. 47(4), 1107-1118 (2009).

-. In-depth evaluation of extraction method and storage conditions for viral load quantification and resistance genotyping.

38 Monleau M, Butel C, Delaporte E, Boillot F, Peeters M. Effect of storage conditions of dried plasma and blood spots on HIV-1 RNA quantification and PCR amplification for drug resistance genotyping. J. Antimicrob. Chemother. 65(8), 1562-1566. (2010).

- Good evaluation of the contribution of proviral DNA in viral load quantification and resistance genotyping from DBS.

39 O'Shea S, Mullen J, Corbett K, Chrystie I, Newell ML, Banatvala JE. Use of dried whole-blood spots for quantification of HIV-1 RNA. AIDS 13(5), 630-631 (1999).

40 Reigadas S, Schrive MH, urillac-Lavignolle V, Fleury HJ. Quantitation of HIV-1 RNA in dried-blood and plasma spots. J. Virol. Methods 161(1), 177-180 (2009).

41 Uttayamakul S, Likanonsakul S, Sunthornkachit R et al. Usage of dried-blood spots for molecular diagnosis and monitoring HIV-1 infection. J. Virol. Methods 128(1-2), 128-134 (2005).

42 Waters L, Kambugu A, Tibenderana H et al. Evaluation of filter paper transfer of whole-blood and plasma samples for quantifying HIV RNA in subjects on antiretroviral therapy in Uganda. J. Acquir. Immune Defic. Syndr. 46(5), 590-593 (2007).

43 Boom R, Sol CJ, Salimans MM, Jansen CL, Wertheim-van Dillen PM, van der Noordaa J. Rapid and simple method for purification of nucleic acids. J. Clin. Microbiol. 28(3), 495-503 (1990).

44 Bruisten S, van Gemen B, Koppelman M et al. Detection of HIV-1 distribution in different blood fractions by two nucleic acid amplification assays. AIDS Res. Hum. Retroviruses 9(3), 259-265 (1993).

45 van Gemen B, Wiel P, van Beuningen $\mathrm{R}$ et al. The one-tube quantitative HIV-1 RNA NASBA: precision, accuracy and application. PCR Methods Appl. 4(4), S177-S184 (1995).
46 Hirsch MS, Gunthard HF, Schapiro JM et al. Antiretroviral drug resistance testing in adult HIV-1 infection: 2008 recommendations of an International AIDS Society - USA panel. Clin. Infect. Dis. 47(2), 266-285 (2008).

47 National Department of Health. National Antiretroviral Treatment Guidelines. Department of Health, Johannesburg, South Africa (2004).

48 Amellal B, Katlama C, Calvez V. Evaluation of the use of dried spots and of differentstorage conditions of plasma for HIV-1 RNA quantification. HIV Med. 8(6), 396-400 (2007).

49 Bertagnolio S, Soto-Ramirez L, Pilon R et al. HIV-1 drug resistance surveillance using dried whole-blood spots. Antivir. Ther. 12(1), 107-113 (2007).

50 Buckton AJ, Bissett SL, Myers RE et al. Development and optimization of an internally controlled dried-blood spot assay for surveillance of human immunodeficiency virus type-1 drug resistance. J. Antimicrob. Chemother. 62(6), 1191-1198 (2008).

51 Garcia-Lerma JG, McNulty A, Jennings C, Huang D, Heneine W, Bremer JW. Rapid decline in the efficiency of HIV drugresistance genotyping from dried-blood spots (DBS) and dried-plasma spots (DPS) stored at $37^{\circ} \mathrm{C}$ and high humidity. J. Antimicrob. Chemother. 64(1), 33-36 (2009).

52 Hallack R, Doherty LE, Wethers JA, Parker MM. Evaluation of dried-blood spot specimens for HIV-1 drug-resistance testing using the Trugene HIV-1 genotyping assay. J. Clin. Virol. 41(4), 283-287 (2008).

53 Hearps AC, Ryan CE, Morris LM, Plate MM, Greengrass V, Crowe SM. Stability of dried-blood spots for HIV-1 drug resistance analysis. Curr. HIV Res. 8(2), 134-140 (2010).

- Thorough evaluation of storage conditions for resistance genotyping.

54 Johannessen A, Holberg-Petersen M, Lövgården G et al. HIV-1 drug-resistance testing on dried-blood spots is feasible and reliable in patients who fail antiretroviral therapy in rural Tanzania. Antivir. Ther. 15, DOI:10.3851/IMP1660 (2010) (Epub ahead of print).

55 Masciotra S, Garrido C, Youngpairoj AS et al. High concordance between HIV-1 drug resistance genotypes generated from plasma and dried-blood spots in antiretroviralexperienced patients. AIDS 21(18), 2503-2511 (2007).

56 McNulty A, Jennings C, Bennett D et al. Evaluation of dried-blood spots for human immunodeficiency virus type 1 drug resistance testing. J. Clin. Microbiol 45(2), 517-521 (2007).
57 Steegen K, Luchters S, Demecheleer E et al. Feasibility of detecting human immunodeficiency virus type 1 drug resistance in DNA extracted from whole blood or dried-blood spots. J. Clin. Microbiol. 45(10), 3342-3351 (2007).

58 Youngpairoj AS, Masciotra S, Garrido C, Zahonero N, de Mendoza C, Garcia-Lerma JG. HIV-1 drug resistance genotyping from dried-blood spots stored for 1 year at $4^{\circ} \mathrm{C}$. J. Antimicrob. Chemother. 61(6), 1217-1220 (2008).

59 Ziemniak C, George-Agwu A, Moss WJ, Ray SC, Persaud D. A sensitive genotyping assay for detection of drug-resistance mutations in reverse transcriptase of HIV-1 subtypes B and C in samples stored as dried-blood spots or frozen RNA extracts. J. Virol. Methods 136(1-2), 238-247 (2006).

60 Bi X, Gatanaga H, Ida S et al. Emergence of protease inhibitor resistance-associated mutations in plasma HIV-1 precedes that in proviruses of peripheral blood-mononuclear cells by more than a year. J. Acquir. Immune Defic. Syndr. 34(1), 1-6 (2003).

61 Venturi G, Romano L, Carli T et al. Divergent distribution of HIV-1 drugresistant variants on and off antiretroviral therapy. Antivir. Ther. 7(4), 245-250 (2002).

62 Nelson JA, Loftis AM, Kamwendo D et al. Nevirapine resistance in human immunodeficiency virus type 1-positive infants determined using dried-blood spots stored for up to 6 years at room temperature. J. Clin. Microbiol. 47(4), 1209-1211 (2009).

63 Garrido C, Zahonero N, Fernandes D et al. Subtype variability, virological response and drug resistance assessed on dried-blood spots collected from HIV patients on antiretroviral therapy in Angola. J. Antimicrob. Chemother. 61(3), 694-698 (2008).

64 Bertagnolio S, Derdelinckx I, Parker M et al. World Health Organization/HIVResNet. Drug resistance laboratory strategy. Antivir. Ther. 13(Suppl 2), 49-57 (2008).

- WHO drug resistance laboratory strategy with recommendations for DBS usage in resource-limited settings.

65 Kamoto K, Berle-Grasse J. Surveillance of transmitted HIV drug resistance with the World Health Organization threshold survey method in Lilongwe, Malawi. Antivir. Ther. 13(Suppl. 2), 83-87 (2008).

66 Somi GR, Kibuka T, Diallo Ket al. Surveillance of transmitted HIV drug resistance among women attending antenatal clinics in Dar es Salaam, Tanzania. Antivir. Ther. 13(Suppl 2), 77-82 (2008). 
67 Mousavi SM, Hamkar R, Gouya MM et al. Surveillance of HIV drug resistance transmission in Iran: experience gained from a pilot study. Arch. Virol. 155(3), 329-334 (2010).

68 Zhang J, Kang D, Fu J et al. Surveillance of transmitted HIV type 1 drug resistance in newly diagnosed HIV type 1-infected patients in Shandong Province, China. AIDS Res. Hum. Retroviruses 26(1), 99-103 (2010).

69 Behets F, Kashamuka M, Pappaioanou M et al. Stability of human immunodeficiency virus type 1 antibodies in whole-blood dried on filter paper and stored under various tropical conditions in Kinshasa, Zaire. J. Clin. Microbiol. 30(5), 1179-1182 (1992).

70 Mwaba P, Cassol S, Pilon R et al. Use of dried whole-blood spots to measure CD $4^{+}$ lymphocyte counts in HIV-1-infected patients. Lancet 362(9394), 1459-1460 (2003).
71 Koal T, Burhenne H, Romling R, Svoboda M, Resch K, Kaever V. Quantification of antiretroviral drugs in dried-blood spot samples by means of liquid chromatography/ tandem mass spectrometry. Rapid Commun. Mass Spectrom. 19(21), 2995-3001 (2005).

72 Malm M, Romsing S, Obua C, Bergqvist Y. Determination of lamivudine, zidovudine and nevirapine in capillary blood sampled on filter paper by LC. J. Chromatogr. Sci. 47(10), 855-862 (2009).

73 Buckton AJ, Prabhu DP, Cane PA, Pillay D. No evidence for cross-contamination of dried-blood spots excised using an office hole-punch for HIV-1 drug resistance genotyping. J. Antimicrob. Chemother. 63(3), 615-616 (2009).

74 Lee HH, Dineva MA, Chua YL, Ritchie AV, Ushiro-Lumb I, Wisniewski CA) Simple amplification-based assay: a nucleic acid-based point-of-care platform for HIV-1 testing. J. Infect. Dis. 201(Suppl 1), S65-S72 (2010).

\section{- Websites}

101 Medecins Sans Frontieres. Untangling the web of antiretroviral price reductions.

MSF (2010).

http://utw.msfaccess.org

(Accessed 23 March 2010)

102 Whatman Ltd. 903 Protein Saver Cards. Whatman Ltd (2010). www.whatman.com/903ProteinSaverCards. aspx

(Accessed 13 Feb 2010) 